\title{
Inflammatory cells as well as epithelial cells in nasal polyps express vascular endothelial growth factor
}

\author{
A. Coste*,**, L. Brugel*, B. Maître**,***, S. Boussat**, J.F. Papon*,**, \\ L. Wingerstmann**, R. Peynègre**, E. Escudier**,
}

Inflammatory cells as well as epithelial cells in nasal polyps express vascular endothelial growth factor. A. Coste, L. Brugel, B. Maitre, S. Boussat, J.F. Papon, L. Wingerstmann, R. Peynegre, E. Escudier. (C) ERS Journals Ltd 2000.

ABSTRACT: In nasal polyps (NPs), locally secreted growth factors are involved in the remodelling of the epithelium and extracellular matrix but little is known concerning vessel remodelling. The in situ expression of vascular endothelial growth factor (VEGF) in NPs and control nasal mucosa (CM) were evaluated and in vitro secretion of VEGF from primary human cultures of nasal epithelial cells (HNECs) was quantified.

VEGF expression was evaluated in $N P(n=14)$ and $C M(n=6)$ after immunolabelling. In supernatants from HNECs cultured at air/liquid interface, VEGF was quantified by immunoassay, under baseline conditions and after transforming growth factor- $\beta 1$ (TGF- $\beta 1$ ) stimulation. In HNEC lysates, VEGF and VEGF messenger ribonucleic acid (mRNA) were detected using Western blot analysis and reverse transcriptase polymerase chain reaction respectively.

VEGF positivity was more frequent in inflammatory cells in NPs (14 of 14) than in CM (three of six) $(p<0.05)$ and in the epithelium in NPs (six of 14) than in CM (two of six) (nonsignificant). Under baseline conditions, the VEGF concentration in HNEC culture medium increased from day 2 to 4 , then decreased and became undetectable. VEGF concentrations increased significantly after TGF- $\beta 1$ stimulation. In HNEC lysates, VEGF and VEGF mRNA were detected on days 4 and 14 of culture.

It was concluded that vascular endothelial growth factor is intensely expressed in situ in nasal polyps, mainly in inflammatory cells but also in epithelial cells. Human nasal epithelial cells are able to secrete in vitro vascular endothelial growth factor. Transforming growth factor- $\beta 1$ upregulates this secretion. This suggests that vascular endothelial growth factor, inducing oedema and angiogenesis, could be involved in the pathogenesis of nasal polyps.

Eur Respir J 2000; 15: 367-372.

Nasal polyposis is a chronic inflammatory disease of the nasal mucosa sometimes affecting patients with allergy, cystic fibrosis or primary ciliary dyskinesia, but mostly occurring in patients without any underlying disease. In all cases, polyps grow in the nasal and paranasal sinus cavities, causing very disabling symptoms and requiring longterm treatment with corticosteroids or even surgery. The pathophysiology of the disease remains unclear and histomorphologic features of nasal polyps (NP) are nonspecific, showing oedema, inflammatory cell infiltration with numerous eosinophils and various degrees of tissue remodelling in epithelium, glands, connective tissue and vessels [1]. Although very few studies have dealt with vascular remodelling in NPs, the modifications of vessels observed in NPs are suggestive of angiogenic processes [2] Moreover, in animal models of NP formation, numerous vessels are present in the stroma of the growing polyps [3, 4]. Vascular remodelling, with local angiogenesis and plasma leakage, could therefore play an important role in the growth process of NPs.
*Dept of Otorhinolaryngology and Head and Neck Surgery, University Hospital Henri Mondor (Assistance Publique des Hôpitaux de Paris) and Intercommunal Hospital, University Paris XII, Créteil, France. **Institut National de la Santé et de la Recherche Médicale (INSERM), U492, Faculté de Médicine, University Paris XII, Créteil, France. ***Dept of Pneumology, University Hospital Henri Mondor (Assistance Publique des Hôpitaux de Paris) and Intercommunal Hospital, University Paris XII, Créteil, France. ${ }^{+}$Dept of Histology, University Hospital Pitié-Salpetrière (Assistance Publique des Hôpitaux de Paris), University Paris VI, Paris, France.

Correspondence: A. Coste, Service d'ORL et de Chirurgie Cervico-Faciale, Hôpital Henri Mondor, 51 Avenue du Maréchal de Lattre de Tassigny, 94010 Créteil, France. Fax: 33149812423

Keywords: Epithelial cells, inflammatory cells, nasal polyps, primary cultures, transforming growth factor- $\beta 1$, vascular endothelial growth factor

Received: May 41999

Accepted after revision October 191999

This work was supported by funds provided by the Délégation à la Recherche Clinique de l'Assistance Publique des Hôpitaux de Paris (grant CRC96059).

process of NPs.

Although numerous factors are involved in vessel remodelling, one of them, vascular endothelial growth factor (VEGF), exhibiting pro-oedematous and angiogenic properties targeted to endothelial cells, could play a key role. VEGF is a dimeric heparin-binding glycoprotein with a molecular weight of $\sim 45 \mathrm{kDa}$. Four different isoforms generated by differential splicing of messenger ribonucleic acid (mRNA) (VEGF 121, VEGF 165, VEGF 189 and VEGF 206) have been identified in humans. VEGF specifically binds to high-affinity receptors with tyrosine kinase activity and these binding sites have been detected in the vast majority of tissues and organs, in which their expression is restricted to microvasular endothelial cells [5]. VEGF induces endothelial cell proliferation and increases vascular permeability and is therefore suspected to be involved in wound healing, tumour growth, and chronic inflammation [5]. Various cell types, including inflammatory and epithelial cells, are able to synthesize VEGF, possibly under the control of other growth factors such as transforming growth factor- $\beta 1$ (TGF- $\beta 1)[6,7]$. 
Interestingly, TGF- $\beta 1$ has been previously demonstrated to be expressed at a high level in NPs $[8,9]$ and several studies recently highlighted the important role of epithelial cells in NP inflammation.

It therefore seemed interesting to investigate the expression of VEGF in NPs. The aim of this study was to evaluate the in situ expression of VEGF protein in NP and control nasal mucosa. The ability of epithelial cells cultured from NPs to release VEGF was quantified and the expression of VEGF mRNA was also analysed in these cells. The ability of TGF- $\beta 1$ to induce VEGF secretion was tested in epithelial cells cultured from NPs.

\section{Material and methods}

\section{Materials}

Twenty-one adult patients (12 males, nine females) suffering from nasal polyposis were included in the study. Patients with cystic fibrosis or primary ciliary dyskinesia were excluded from this study because of the special features of their NPs. The diagnosis of nasal polyposis was established on the basis of medical history and symptoms, endoscopic examination of the nose and computed tomographic evalucation of the nasal fossae and paranasal sinuses. NPs were sampled in all patients at the beginning of the surgical procedure (endoscopic endonasal ethmoidectomy). All patients were asked to stop general and/or local nasal treatment 1 month prior to surgery. Six nonsmoking adult patients who underwent rhinoplasty were included as controls; all were free of symptoms of nasal inflammation with a normal appearance of the nasal mucosa on endoscopic examination. Nasal mucosa (CM) from the inferior turbinate was sampled in controls at the beginning of the surgical procedure. This protocol was approved by the review and ethics committee of the authors' institution (Comité Consultatif de Protection des Personnes pour la Recherche Biomédicale-Henri Mondor).

\section{Immunohistochemistry}

Fourteen NPs and six CM obtained from different patients, were immediately fixed in formaldehyde, then paraffin-embedded and 5 - $\mu \mathrm{m}$ sections obtained. For each sample, a section was systematically stained (haemalum/ eosin/saffron) for standard histomorphological analysis. VEGF was detected in nasal tissues using a specific murine monoclonal antibody (MAB293, R\&D Systems Europe, Oxon, UK) and negative controls were performed using an isotype-matched murine monoclonal antibody (MAB004, R\&D Systems Europe). After deparaffinization, slides were incubated in distilled water and then in $0.01 \mathrm{M}$ phosphatebuffered saline (pH 7.4) (PBS) with $0.125 \mathrm{mg} \cdot \mathrm{mL}^{-1}$ protease type XXIV (Sigma Chemicals, St Louis, MI, USA) $\left(37^{\circ} \mathrm{C}, 15 \mathrm{~min}\right.$ each time). After rinsing and incubating the slides with tris (hydroxymethyl)aminomethane (Tris)buffered saline (TBS $0.015 \mathrm{M}, \mathrm{pH}$ 7.6) (room temperature $\left.\left(\sim 20^{\circ} \mathrm{C}\right), 5 \mathrm{~min}\right)$, nonspecific antigenic sites were saturated with bovine serum albumin, and the slides incubated with anti-human VEGF antibody or negative control antibody (both at a concentration of $12.5 \mu \mathrm{g} \cdot \mathrm{mL}^{-1}$ ) in a moist chamber overnight $\left(4^{\circ} \mathrm{C}\right)$. All subsequent incubations were performed at room temperature and the slides washed in TBS between each incubation. The slides were incubated with a biotinylated rabbit antimouse antibody (Dako, Glostrup, Denmark), then with a streptavidin/alkaline phosphatase complex (Dako) and finally revelation substrate (i.e. 3-hydroxy-2-naphthoic acid 4'-chloro-2'-methylanilide (naphthol AS-TR) phosphate, fast red 4-chloro-2-methylbenzene diazonium (TR) salt, Sigma) was added and incubated in the dark for $20 \mathrm{~min}$. Tissue sections were counterstained with haematoxylin. All tissue sections were examined using a light microscope (final magnification $\times 500$ ), and the number of positive cells in the whole sections was evaluated by two independent investigators in the inflammatory cells from the lamina propria, the epithelial cells and the vessels using a semiquantitative scale (-: absence of positivity; +: rare positivity; ++ : moderate positivity; +++: high positivity).

\section{Primary cultures of human nasal epithelial cells}

Epithelial cells dissociated from NPs, obtained from five different patients, were cultured at an air/liquid interface according to the technique described by YAMAYA et al. [10]. Briefly, NPs were sampled, immediately suspended in Dulbecco's Modified Eagle's medium (DMEM, Life Technologies, Cergy-Pontoise, France)/Ham's F-12 nutrient medium (F12, Life Technologies) and stored at $4{ }^{\circ} \mathrm{C}$ for primary culture of human nasal epithelial cells (HNECs). Each NP sampled was rinsed in PBS containing dithiothreitol $(5 \mathrm{nM})$ and antibiotics $\left(100 \mathrm{U} \cdot \mathrm{mL}^{-1}\right.$ penicillin, $100 \mathrm{mg} \cdot \mathrm{mL}^{-1}$ of streptomycin, $2.5 \mu \mathrm{g} \cdot \mathrm{mL}^{-1}$ of amphotericin $\mathrm{B}$ and $100 \mathrm{mg} \cdot \mathrm{mL}^{-1}$ of gentamycin) and then placed in a PBS/antibiotics solution containing $0.1 \%$ pronase (Sigma) overnight at $4{ }^{\circ} \mathrm{C}$. The samples were incubated in DMEM/F12 containing 5\% foetal calf serum (FCS) before centrifugation $(1,000 \times g, 7 \mathrm{~min})$. The cell pellets were then suspended in $0.25 \%$ trypsin/ethylene diamine tetra-acetic acid EDTA solution (Life Technologies) for $3 \mathrm{~min}$ diluted into DMEM/F12/antibiotics containing $10 \% \mathrm{FCS}$ and incubated before centrifugation and resuspension. Finally, $10^{6}$ cells $\cdot$ well $^{-1}$ were plated in inserts (12 mm; Transwell, Costar, Cambridge, MA, USA) with 12-mm-diameter type IV collagen-coated (Sigma) polycarbonate microporous membranes and incubated in $5 \% \mathrm{CO}_{2}$ at $37^{\circ} \mathrm{C}$. For the first $24 \mathrm{~h}$, cells were incubated with $1 \mathrm{~mL}$ of DMEM/F12/antibiotics containing 2\% Ultroser G (GibcoBRL, Life Technologies, Cergy Pontoise, France) outside the insert and DMEM/F12/antibiotics containing $10 \%$ FCS inside the insert. After $24 \mathrm{~h}$, the media outside the insert were changed and those inside the insert removed in order to place the cells at an air/liquid interface, and media outside the insert were then changed daily. Aliquots $(1 \mathrm{~mL})$ of HNEC cultures were saved and stored at $-20^{\circ} \mathrm{C}$ after daily changing until day 21 of culture. The epithelial nature of the cultured cells was confirmed via flow cytometric analysis of cytokeratin immunofluorescence labelling showing $>95 \%$ positive cells on day 3 and $>99 \%$ positive cells on day 7 .

\section{Transforming growth factor- $\beta 1$ stimulation of human nasal epithelial cells}

On days 3, 6 and 13, the culture medium was removed and replaced with a defined medium (DMEM/F12/antibiotics supplemented with $1 \%$ insulin, $0.1 \%$ hydrocortisone and $0.25 \%$ epidermal growth factor) in the presence 
or absence of natural human TGF- $\beta 1$ (Sigma) at a concentration of $5 \mathrm{ng} \cdot \mathrm{mL}^{-1}$ for $24 \mathrm{~h}$. After $24 \mathrm{~h}$, the media were removed and stored at $-20^{\circ} \mathrm{C}$. Each condition was performed in duplicate in four different cultures of HNECs.

Quantification of vascular endothelial growth factor in supernatants from human nasal epithelial cells by immunoassay

VEGF was detected and quantified in the culture medium samples using a quantitative sandwich enzyme immunoassay (Quantikine VEGF Immunoassay; R\&D systems). Briefly, recombinant human VEGF standard concentrations, culture medium alone and HNEC supernatant samples were incubated for $2 \mathrm{~h}$ in microtitre wells precoated with antihuman VEGF mouse monoclonal antibody, in duplicate. The wells were then aspirated and washed three times and antihuman VEGF polyclonal antibody conjugated to horseradish peroxidase was added and incubated for $2 \mathrm{~h}$. After three washes, substrate solution containing tetramethylbenzidine as chromogen was added and incubated for $20 \mathrm{~min}$ until the reaction was stopped with sulphuric acid. The microtitre plate was immediately read in a photocolorimeter (Dynatech MRX; Dynatech Guyancourt, France) at $450 \mathrm{~nm}$.

Detection of vascular endothelial growth factor in human nasal epithelial cell lysates by Western blot analysis

Whole cell lysates were prepared from two different cultures on days 4 and 14 by scraping HNLCs from filters in lysis buffer containing $10 \mathrm{mM}$ Tris and $1 \%$ sodium dodecylsulphate $(\mathrm{pH}$ 7.4). The protein content in the various cell lysates was determined according to the method of O.H. Lowry as modified for the DC protein assay (BioRad, Hercules, CA, USA) and samples $\left(15 \mu \mathrm{g} \cdot\right.$ lane $\left.^{-1}\right)$ were subjected to $10 \%$ polyacrylamide gel electrophoresis. The separated peptides were then transferred electrophoretically on to nitrocellulose membranes, which were incubated overnight with a blocking solution. VEGF was detected by incubating the membranes with a polyclonal rabbit antihuman VEGF antibody (Santa-Cruz, Le Perray, France) $\left(1: 500,1 \mathrm{~h}, 4^{\circ} \mathrm{C}\right)$ and then with peroxidaseconjugated goat antirabbit immunoglobulin $\mathrm{G}$ (Dako). Finally, VEGF was revealed using the electrochemiluminescence detection system (Amersham, Les Ulis, France).

Detection of vascular endothelial growth factor messenger ribonucleic acid in human nasal epithelial cells using the reverse transcriptase polymerase chain reaction

On days 4, 14 and 21, total cellular ribonucleic acid (RNA) was isolated using the RNAplus system (Bioprobe System, Montreuil, France), and quantified at 260/ $280 \mathrm{~nm}$, and the integrity of the samples was checked by means of $1.5 \%$ agarose gel electrophoresis. Total RNA (2 $\mu \mathrm{g})$ was converted to complementary deoxyribonucleic acid (DNA) (cDNA) using 5 U Moloney murine leukaemia virus reverse transcriptase (RT) and $0.5 \mu \mathrm{g}$ oligodeoxythymidine $\left(1 \mathrm{~h}, 37^{\circ} \mathrm{C}\right)$. RT-generated cDNA encoding VEGF and $\beta$-actin (a control of the integrity of RNA and an internal standard) were amplified by means of the polymerase chain reaction (PCR). Amplification of $5 \mu \mathrm{L}$
RT-generated cDNA was performed with $0.2 \mathrm{nM}$ sense (5'-CCATGAACTTTCTGCTCTCTTG-3') and antisense ( $5^{\prime}$ GGTGAGAGGTCTAGTTCCCG-3') primers of VEGF and $2.5 \mathrm{U}$ Taq polymerase. ${ }^{32} \mathrm{P}$-labelled deoxycytidine triphosphate $(0.3 \mu \mathrm{M})$ was added to each sample, which was amplified for 35 cycles of PCR (denaturation: 1 min, $94^{\circ} \mathrm{C}$; extension: $3 \mathrm{~min}, 72^{\circ} \mathrm{C}$ ). The annealing time was 2 min and the annealing temperature was $<55^{\circ} \mathrm{C}$ for the VEGF transcript. PCR products were then electrophoresed in a polyacrylamide gel $(100 \mathrm{~V}, 1 \mathrm{~h})$ and the amplified products were visualized by autoradiography (24-48 h at $-80^{\circ} \mathrm{C}$ ). The authenticity of the amplified products was confirmed by direct nucleotide sequencing of the amplified RT-PCR products. All RT-PCR studies were performed at least four times with RNA from two different cultures.

\section{Statistical analysis}

In situ VEGF positivity in inflammatory cells, epithelial cells and vessel walls from NPs and CM were compared using Fischer's exact test. VEGF concentrations in HNEC culture medium in the presence and absence of TGF- $\beta 1$ were compared using the Wilcoxon signed-rank test. A pvalue of $<0.05$ was considered to be significant.

\section{Results}

In situ vascular endothelial growth factor expression in nasal polyps and control nasal mucosa

All NPs exhibited morphological features of intense inflammation with an infiltrate rich in inflammatory cells. In NPs and CM, VEGF was mainly expressed in inflammatory and epithelial cells (fig. 1). Vascular endothelial cells were negative for VEGF, but VEGF was exceptionally detected in some cells of the NP vessel walls. The pattern of VEGF-positivity was homogenous in the cytoplasm of inflammatory cells. Conversely, in the epithelium, VEGF expression was concentrated in different epithelial areas. In epithelial cells, VEGF-positivity was cytoplasmic and granular, in a vacuolar pattern concentrated just above the nucleus. Quantitatively, VEGF was always expressed in the numerous inflammatory cells of NPs (14 of 14) and rarely expressed in the few inflammatory cells of the three of CM (three of six) and this

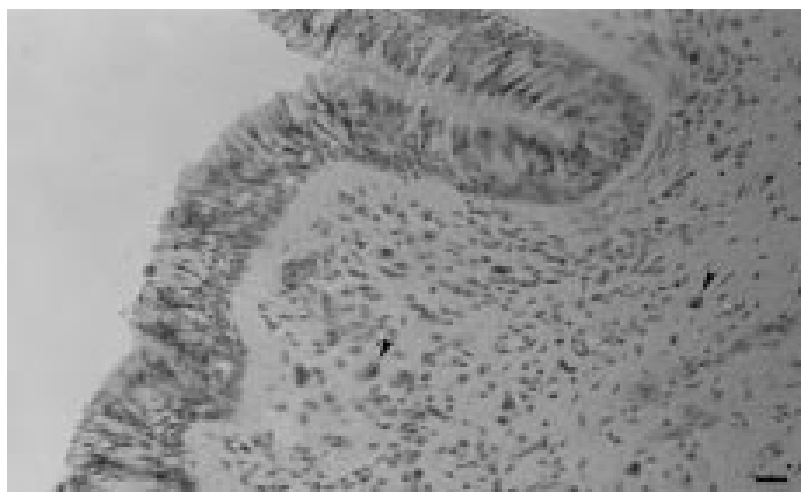

Fig. 1. - Immunodetection of vascular endothelial growth factor in a nasal polyp. Diffuse cytoplasmic labelling is observed in inflammatory cells (arrowheads), whereas supranuclear labelling is seen in epithelial cells. (Internal scale bar $=20 \mu \mathrm{m}$.) 
Table 1. - Semiquantitative evaluation of the number of vascular endothelial growth factor epithelium, the inflammatory infiltrate and the walls of vessels in nasal polyps and normal nasal mucosa

\begin{tabular}{lccc}
\hline Subject No. & Epithelium & Inflammatory cells & Vessels \\
\hline Polyps & & + & \\
1 & ++ & + & ++ \\
2 & + & + & - \\
3 & + & ++ & - \\
4 & - & + & - \\
5 & - & + & - \\
6 & - & + & - \\
7 & + & ++ & + \\
8 & +++ & + & - \\
9 & - & ++ & - \\
10 & +++ & + & - \\
11 & - & + & + \\
12 & - & +++ & - \\
13 & - & & - \\
14 & - & - & + \\
Mucosa & - & - & - \\
1 & - & + & - \\
2 & +++ & - & - \\
3 & - & + & - \\
4 & - & + & - \\
5 & + & & - \\
6 & & + &
\end{tabular}

-absence of positivity; +: rare positivity; ++: moderate positivity; +++: high positivity.

difference was statistically significant $(\mathrm{p}=0.01)$ (table 1$)$. Epithelial VEGF-positivity was also more frequent in NPs (six of 14) than in CM (two of six) but the difference was not statistically significant (table 1).

Vascular endothelial growth factor secretion in human nasal epithelial cells

Under baseline culture conditions, VEGF concentrations in culture medium increased from day 2 to day 4 , and then decreased until day 7 when they became undetectable (fig. 2). VEGF concentrations after stimulation with TGF$\beta 1$ increased significantly compared to controls $(p=0.03)$. The concentration (TGF- $\beta 1$ stimulation versus control, mean \pm SD) were $910 \pm 362$ versus $542 \pm 341 \mathrm{pg} \cdot \mathrm{mL}^{-1}$ on day

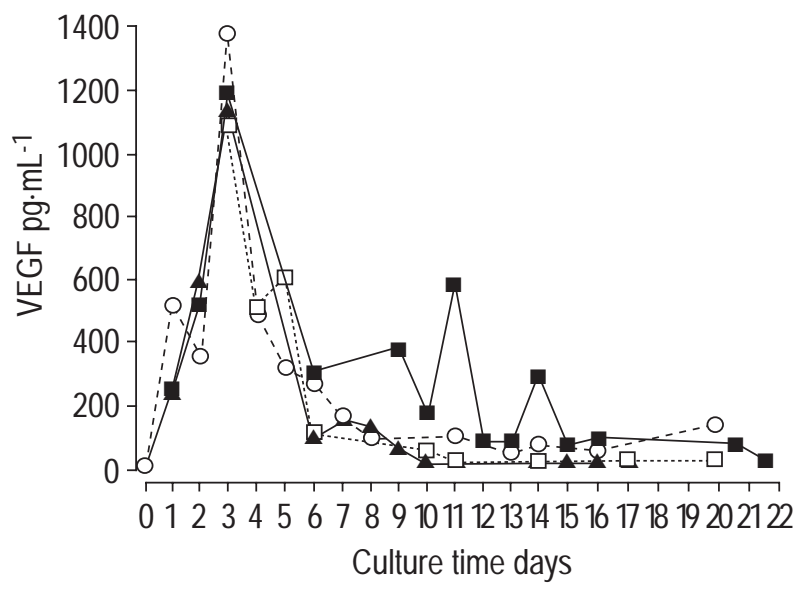

Fig. 2. - Vascular endothelial growth factor (VEGF) concentrations in human nasal epithelial cell culture supernatants under baseline conditions, days 1-22. $\square$ : culture $1 ; \boldsymbol{\Delta}$ : culture $2 ; \bigcirc$ : culture $3 ; \square$ : culture 4 .

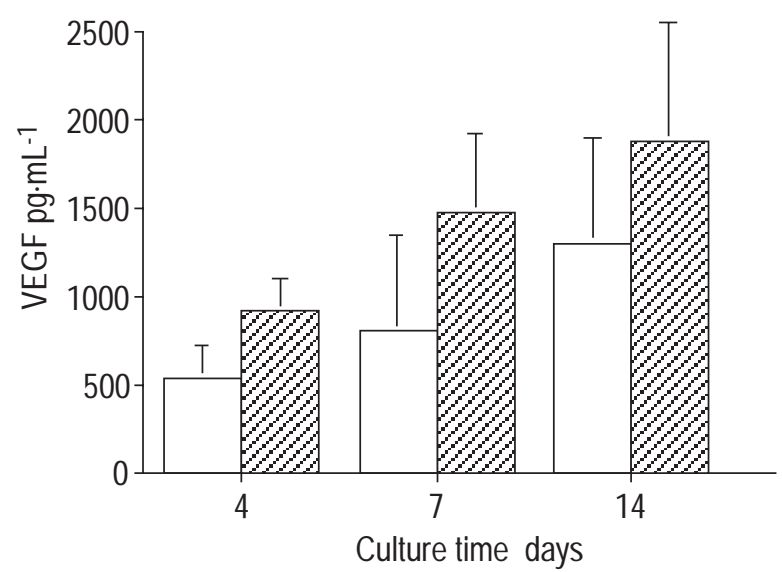

Fig. 3. - Vascular endothelial growth factor (VEGF) concentrations (mean \pm SEM) in human nasal epithelial cell supernatants from four different cultures under control conditions ( $\square$ ) or after $24 \mathrm{~h}$ of stimulation with 5 $\mathrm{ng} \cdot \mathrm{mL}^{-1}$ transforming growth factor- $\beta 1(\mathbb{Z})$ at various culture times.

$41,462 \pm 892$ versus $800 \pm 1,022 \mathrm{pg} \cdot \mathrm{mL}^{-1}$ on day 7 and $1,870 \pm 1,152 \mathrm{pg} \cdot \mathrm{mL}^{-1}$ versus $1,288 \pm 1,022 \mathrm{pg} \cdot \mathrm{mL}^{-1}$ on day 14 of culture (fig. 3 ).

Vascular endothelial growth factor detection in human nasal epithelial cell

Western blot analysis revealed VEGF in HNEC lysates on days 4 and 14 of culture, with more intense expression on day 4 than on day 14 (fig. 4 ).

Reverse transcriptase polymerase chain reaction detection of vascular endothelial growth factor messenger ribonucleic acid in human nasal epithelial cells

VEGF mRNA was detected in HNEC cultures on days 4, 14 and 21 (fig. 5).

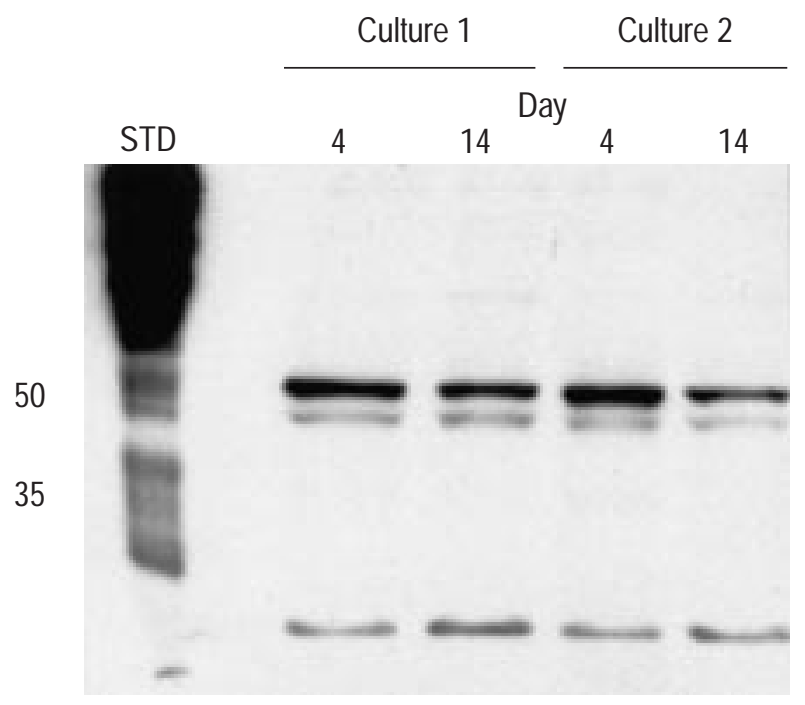

Fig. 4. - Detection of vascular endothelial growth factor (VEGF) via Western immunoblots. The total protein $(15 \mu \mathrm{g})$ extracted from two different human nasal epithelial cell cultures on days 4 and 14 were run on the four lanes and a rabbit polyclonal antihuman VEGF used for detection. VEGF was detected in its dimeric $45 \mathrm{kDa}$ form: intensely on day 4 and moderately on day 14 . In addition, a band at $12 \mathrm{kDa}$ was detected in all lanes, probably due to the presence of the monomeric form of VEGF. STD: molecular weight standards $(\mathrm{kDa})$. 
VEGF

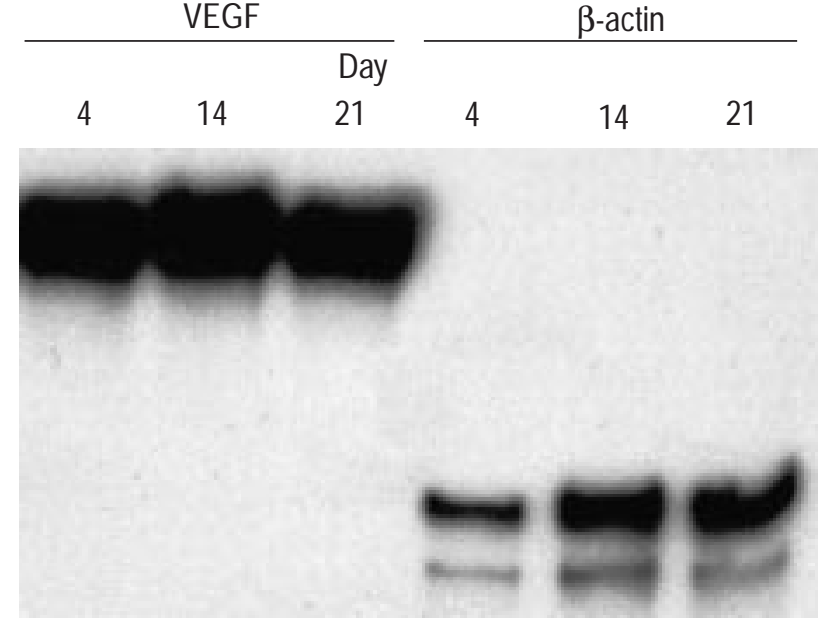

Fig. 5. - Detection of vascular endothelial growth factor (VEGF) messenger ribonucleic acid (RNA) with ${ }^{32} \mathrm{P}$-labelled reverse transcriptase polymerase chain reaction in one primary human nasal epithelial cell (HNEC) culture on days 4, 14 and 21. $\beta$-Actin was used as a control of the integrity of RNA and as an internal standard. These results were reproduced in two HNEC cultures.

\section{Discussion}

Although angiogenesis appears to be an important event in NP pathogenesis, little is known about the mechanisms of this vascular remodelling. In the present study, the expression of the angiogenic growth factor VEGF was investigated and, for the first time, it was shown that VEGF is intensely expressed in inflammatory cells in human NP in contrast with the low expression found in normal nasal mucosa. Intense expression of VEGF in inflammatory cells is not surprising since inflammatory cells, especially macrophages, intensely express VEGF mRNA in various inflammatory states, such as wound healing, psoriasis and rheumatoid arthritis [11]. It has been already shown by in situ hybridization that scattered plasma cells in the stroma of human NPs express VEGF mRNA [12]. In addition to macrophages, eosinophils, especially active and abundant in NPs [13] and known to express both VEGF and mRNA in vitro [14], could also contribute to the local production of VEGF. Interestingly, numerous epithelial areas were positive for VEGF in NPs, whereas only sparse areas were detected in CM. In epithelial cells, the pattern of VEGF immunostaining was singular, concentrated in large vacuoles in supranuclear areas contrasting with the diffuse positivity observed in inflammatory cells. A similar pattern has also been described in the glandular cells of the human adult intestine [15], suggesting cytoplasmic storage in epithelial cells, as has been evoked in epithelial cells from salivary glands [16].

As VEGF was frequently detected in the epithelial cells of NPs in this study, it seemed of interest to further investigate in vitro VEGF secretion by these cells. Therefore, the in vitro release of VEGF into the culture medium of HNECs was studied. Under baseline culture conditions, although VEGF mRNA was detected during the 3 weeks of culture, VEGF seemed to be secreted only for the first few days of culture. It should be stressed that HNECs cultured at an air/liquid interface, proliferated intensely during the first week and became more differentiated during the second and third weeks of culture, as demonstrated by flow cytometry (propidium iodide DNA labelling) and electron microscopy (presence of secretory and ciliated cells), respectively [17]. It could therefore be speculated that, in vitro, HNECs release VEGF while proliferating. Conversely, although differentiated HNECs still expressed VEGF and VEGF mRNA (shown by Western blot and RT-PCR analysis, respectively), VEGF was not detected in the culture medium. One possible explanation could be downregulation of VEGF synthesis in differentiated HNECs, as suggested by the results of VEGF Western blot analysis. Another explanation could be storage of VEGF in differentiated HNECs. This latter hypothesis could be supported by the vacuolar pattern of VEGF immunostaining observed in situ in epithelial cells from NPs and CM, as in other epithelial cells $[15,16]$.

Since, on the one hand, TGF- $\beta 1$ has been shown to increase VEGF expression in the A549 airway cell line [6] and, on the other, it is at a high level expressed in NPs [8, 9], it was interesting to show that TGF- $\beta 1$ increased VEGF release by cultured HNECs. In NPs, TGF- $\beta 1$ locally secreted by macrophages and eosinophils could act in a paracrine fashion on epithelial cells to induce VEGF secretion in vivo. The mechanism of this TGF- $\beta 1$-induced VEGF upregulation needs to be clarified; is it a transcriptional or post-transcriptional action of TGF- $\beta 1$, or could TGF- $\beta 1$ induce exocytosis of VEGF in HNECs?

The intense expression of VEGF in NPs compared to CM suggests that VEGF could play a role in NP pathogenesis. NPs are growing tissues with epithelial proliferation and extracellular matrix accumulation [3, 4, 18]. These growth processes require an increased vascular supply, which could be, at least partly, regulated by VEGF [5], locally released by inflammatory cells and possibly to a certain extent by epithelial cells. As previously suggested, besides these effects on angiogenesis, VEGF could also increase microvascular permeability and therefore contribute to the oedema frequently observed in NPs [12] Moreover, this increased microvascular permeability could lead to the extravasation of plasma proteins participating in the accumulation of extracellular matrix and thereby contributing to the growth of NPs.

In contrast with the intense expression of VEGF in NPs, it should be stressed that VEGF was also present in CM. VEGF has also been detected in other normal human adult epithelia, e.g. in the bronchus, intestine [15], salivary glands [16] and skin [19]. In the skin, it has been speculated that keratinocyte-derived VEGF could regulate skin vessel function under normal physiological conditions [19]. A similar hypothesis could be proposed in nasal mucosa where, as in the skin, the nasal epithelium is not directly vascularized and is dependent for its nutrition on stromal microvessels. After being damaged, nasal epithelial cells could rapidly release VEGF, and increase vascular permeability and endothelial cell proliferation in order to facilitate their own survival and the healing process.

This study shows for the first time that vascular endothelial growth factor protein is intensely expressed in nasal polyps, not only in inflammatory cells but also in epithelial cells. Vascular endothelial growth factor could be involved in nasal polyp pathogenesis via induction of angiogenesis and increased microvascular permeability. The present study also shows that nasal polyp epithelial cells are able to 
express vascular endothelial growth factor messenger ribonucleic acid in vitro and secrete vascular endothelial growth factor protein, with up-regulation by TGF- $\beta 1$. Apart from vascular endothelial growth factor overproduction by inflammatory cells and in addition to the various roles of epithelial cells already reported in nasal polyp pathogenesis [18, 20-22], epithelial cells may also act directly on the development of nasal polyp via local vascular endothelial growth factor secretion. TGF- $\beta 1$, by virtue of its ability to upregulate vascular endothelial growth factor, seems to be a key cytokine in the interactions between epithelial and endothelial cells. A better understanding of these microenvironmental mechanisms could help to elucidate the pathophysiology of nasal polyposis and possibly define new therapeutic strategies.

Acknowledgements. The authors wish to thank M. Gouge for technical assistance.

\section{References}

1. Hellquist H. Histopathology. In: Settipane G, Lund V, Bernstein J, Tos M, eds. Nasal Polyps: Epidemiology, Pathogenesis and Treatment. Providence (RI), OceanSide Publications, Inc., 1997; pp. 31-39.

2. Watanabe K, Komatsuzaki A. Ultrastructural findings of capillaries in nasal polyps. Rhinology 1992; 30: 49-56.

3. Larsen PL, Tos M, Kuijpers W, van der Beek JMH. The early stages of polyp formation. Laryngoscope 1992; 102: 670-677.

4. Norlander T, Westrin KM, Fukami M, Stierna P, Carlsöö B. Experimentally induced polyps in the sinus mucosa: a structural analysis of the initial stages. Laryngoscope 1996; 106: 196-203.

5. Ferrara N, Houck K, Jakeman L, Leung DW. Molecular and biological properties of the vascular endothelial growth factor family of proteins. Endocr Rev 1992; 13: 18-32.

6. Pertovaara L, Kaipainen A, Mustonen T, et al. Vascular endothelial crowth factor is induced in response to transforming growth factor- $\beta$ in fibroblastic and epithelial cells. J Biol Chem 1994; 269: 6271-6274.

7. Frank S, Hübner G, Breier G, Longaker MT, Greenhalgh DG, Werner S. Regulation of vascular endothelial growth factor expression in cultured keratinocytes. $J$ Biol Chem 1995; 270: 12607-12613.

8. Ohno I, Lea RG, Flanders $\mathrm{KC}$, et al. Eosinophils in chronically inflamed human upper airway tissue express transforming growth factor $\beta 1$ gene (TGF $\beta 1) . J$ Clin Invest 1992; 89: 1662-1668.

9. Elovic A, Wong DTW, Weller PF, Matossian K, Galli SJ. Expression of transforming growth factor- $\alpha$ and $\beta 1$ messenger RNA and product by eosinophils in nasal polyps. J Allergy Clin Immunol 1994; 93: 864-869.
10. Yamaya M, Finkbeiner W, Chun S, Widdicombe J. Differentiated structure and function of cultures from human tracheal epithelium. Am J Physiol 1992; 262: L713-L724.

11. Dvorak HF, Detmar M, Claffey KP, Nagy JA, van de Water L, Senger DR. Vascular permeability factor/vascular endothelial growth factor: an important mediator of angiogenesis in malignancy and inflammation. Int Arch Allergy Immunol 1995; 107: 233-235.

12. Ito A, Hirota $\mathrm{S}$, Mizuno $\mathrm{H}$, et al. Expression of vascular permeability factor (VPF/VEGF) messenger RNA by plasma cells: possible involvement in the development of oedema in chronic inflammation. Pathol Int 1995; 45: $715-720$.

13. Stoop AK, van der Heijden HAMD, Biewenga J, van der Baan S. Eosinophils in nasal polyps and nasal mucosa: an immunohistochemical study. J Allergy Clin lmmunol 1993; 91: 616-622.

14. Horiuchi T, Weller PF. Expression of vascular endothelial growth factor by human eosinophils: upregulation by granulocute macrophage colony-stimulating factor and interleukin-5. Am J Respir Cell Mol Biol 1997; 17: 70-77.

15. Shifren JL, Doldi N, Ferrara N, Mesiano S, Jaffe RB. In the human fetus, vascular endothelial growth factor is expressed in epithelial cells and myocytes, but not vascular endothelium: implications for mode of action. $J$ Clin Endocrinol Metab 1994; 79: 316-322.

16. Taichman N, Cruchley A, Flechter L, et al. Vascular endothelial growth factor in normal human salivary glands and saliva: a possible role in the maintenance and homeostasis. Lab Invest 1998; 78: 869-875.

17. Escudier E, Brugel L, Papon J, et al. Human nasal epithelial cells cultured at air-liquid interface develop respiratory differentiation. Allergologie 1998; 21: 561.

18. Coste A, Wang Q, Roudot-Thoraval F, et al. Epithelial cell proliferation in nasal polyps could be up-regulated by platelet-derived growth-factor. Laryngoscope 1996; 106: 578-583.

19. Weninger W, Uthman A, Pammer J, et al. Vascular endothelial growth factor production in normal epidermidis and in benign and malignant epithelial skin tumors. Lab Invest 1996; 75: 647-657.

20. Vignola AM, Crampette L, Mondain M, et al. Inhibitory activity of loratadine and decarboethoxyloratadine on expression of ICAM-1 and HLA-DR by nasal epithelial cells. Allergy 1995; 50: 200-203.

21. Mullol J, Xaubet A, Gaya A, et al. Cytokine gene expression and release from epithelial cells. A comparison study between healthy nasal mucosa and nasal polyps. Clin Exp Allergy 1995; 25: 607-615.

22. Bernstein JM, Gorfien J, Noble B, Yankaskas JR. Nasal polyposis: immunohistochemistry and bioelectrical findings (a hypothesis for the development of nasal polyps). $J$ Allergy Clin Immunol 1997; 99: 165-175. 